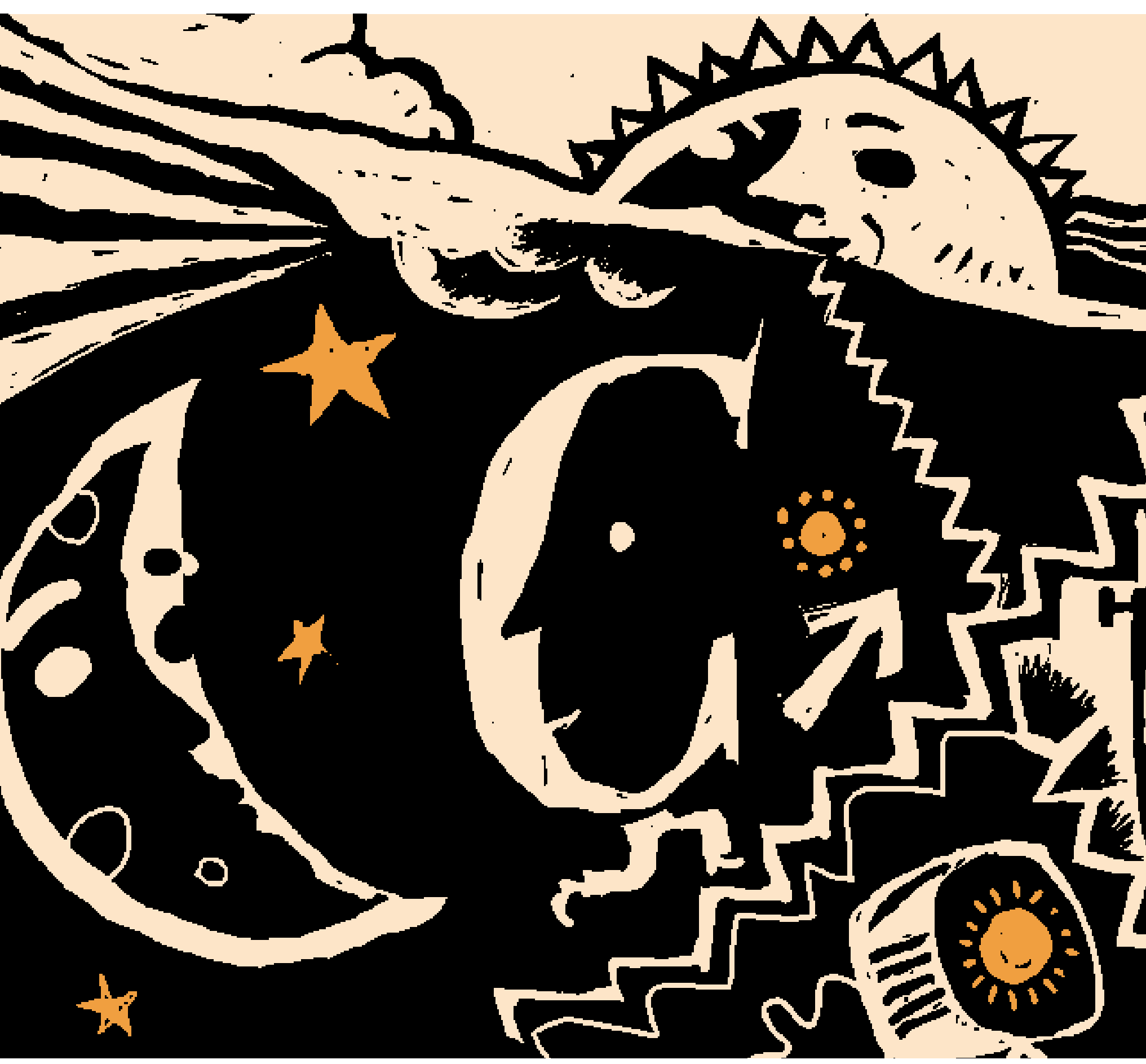




\section{Comunicação \\ e gestão de mudanças estudo de caso em uma indústria química}

Patrícia Felisbino

- Especialista em Gestão Estratégica em Comunicação

Organizacional e Relações Públicas pela ECA-USP

- Pedagoga, Coordenadora de Recursos Humanos na Oxiteno

- patricia felisbino@ hotmail.com

- patricia.felisbino@ oxiteno.com.br 


\section{Resumo}

Este artigo discute e analisa as contribuições da comunicação na gestão de mudanças em contextos empresariais e seu papel na obtenção da participação e comprometimento dosfuncionários. Foi investigada a adoção da perspectiva humanista de comunicação que considera os funcionários como agentes na construção do futuro e da cultura organizacionais. A autora demonstra os resultados da investigação empírica, com estudo de caso sobre mudança realizada numa indústria química. As conclusões evidenciam que o emprego de ações de comunicação facilita a condução de mudanças organizacionais.

PALAVRAS-CHAVE: COMUNICAÇÃo • COMUNICAÇÃo ORGANIZACIONAL • GESTÃo de MUdANÇAS

\section{Abstract}

This article discusses and analyzes the contributions of communication to change management in corporate environments and its role in obtaining the employees' participation and commitment. The adoption of the humanist communication approach, which considers employees as the agents who will build the organization's future and culture has been investigated. The author presents empirical results through a case study of the changes implemented in a chemical plant. The conclusions show that communication actions make it easier to implement organizational changes.

KEY-WORDS: COMMUNICATION - ORGANIZATIONAL COMMUNICATION - CHANGE MANAGEMENT

\section{Resumen}

Este artículo discute y analisa las contribuciones de la comunicación en la gestión de cambios en contextos empresariales y su papel en el proceso de obtención de participación y compromiso de los empleados. Se analizó la adopción de la perspectiva humanista de comunicación. Dicha perspectiva considera los empleados como agentes en la construcción del futuro y de la cultura de la organización. La autora presenta resultados empíricos de un estudio de caso único acerca de los cambios observadosen una industria química. Las conclusiones muestran que las acciones de comunicación facilita la conducción de cambios organizacionales.

PALABRAS CLAVE: COMUNICACIÓN • COMUNICACIÓN ORGANIZACIONAL • GESTIÓN DE CAMBIOS 


\title{
Introdução
}

\begin{abstract}
A empresa do conhecimento deve encontrar novas soluções para responder rapidamente aos clientes, criar novosmercados, desenvolver e dominar com agilidade novos produtos e tecnologias (N onaka, 2000). N este ambiente, a qualidade, enão só a quantidade, é importante. Para tanto, é preciso que os conhecimentos individuais sejam socializados, articulados, combinados e internalizados. Pelo compartilhamento do conhecimento, dá-se o compartilhamento do poder. Neste cenário, o comprometimento com os objetivos da empresa não é estabelecido por meio de ordens, mas sim pelo compartilhamento da visão.
\end{abstract}

Diante destes desafios, a perspectiva de comunicação dos estudos culturais se faz bastante adequada ao atual contexto empresarial. A participação ativa dosindivíduos no processo comunicativo e na caracterização da cultura organizacional é inevitável. $E$ as ações de comunicação interna se mostram como meio de interação contínua entre empresa e funcionários, para alinhar e harmonizar objetivos individuais e institucionais que, não raro, são divergentes.

Atualmente, nas organizações, se discute muito como medir resultados em Comunicação. N este presente artigo - derivado da monografia de conclusão do curso Gestão Estratégica em Comunicação Organizacional e Relações Públicas da Escola de Comunicação e Artes da Universidade de São Paulo (ECA/ USP) - analisaremos este assunto sob o ponto de vista das contribuições das ações dirigidas ao público interno, especialmente em processos de mudança.

A mensuração de resultados de comunicação interna não passa apenas pela comparação entre investimentos versus benefícios financeiros. Ela deve considerar também a ética no relacionamento com o público interno, a possibilidade de desenvolvimento dos colaboradores e a qualidade do clima (percepção dos funcionários a respeito das políticas, procedimentos, valores e forma de relacionamento da empresa com seus públicos estratégicos). Afinal, é basicamente deste público de que se depende para a obtenção de resultados para a organização.

Para Grouard e M eston (2001), qual quer processo de condução de mudança deve respeitar dez passos, quais sejam: definir a Visão, mobilizar, catalisar, dirigir, realizar, obter a participação, lidar com questões de poder, lidar com emoções, treinar e comunicar. As mudanças podem variar em profundidade, velocidade e forma de 
implementação. Por isto, estratégia, estrutura, cultura, sistemas, estilo de gestão e pessoas da organização devem ser levados em conta para que a mudança seja conduzida respeitando estas variáveis.

\section{0 estudo de caso: o desafio de implantar} um Sistema Integrado numa Indústria Química

A Oxiteno é uma empresa brasileira que atua na área química e petroquímica, produzindo matéria-prima para indústrias de alimentos, detergentes, cosméticos, extração de petróleo e tintas, entre outros segmentos. Suas unidades estão localizadas em: Camaçari (BA), Mauá(SP), Tremembé (SP) e Triunfo (RS) ${ }^{1}$. Por ser uma indústria de alto nível de automação, seu corpo funcional (930 funcionários) possui escolaridade mínima de nível médio.

Em 2002, a O xiteno optou pela implantação de um sistema integrado sendo esta uma ação importante para o alcance de seus objetivos estratégicos. Com a integração e redução do número de sistemas, redução de processos manuais, de planilhas eletrônicas e eliminação de erros e a migração de uma visão modular/ departamental para uma visão integrada, a empresa teve como objetivo preparar sua estrutura para suportar o crescimento.

0 projeto ocorreu de julho de 2002 a maio de 2003 e, do ponto de vista da comunicação, o grande desafio era envolver mais de $70 \%$ dos funcionários na mudança. Seriam fundamentais ações de transferência do conhecimento, gerenciamento dos formadores de opinião, obtenção de comprometimento, nivelamento de informações e expectativas e a identificação de indivíduos ou grupos que sofreriam impactos e/ ou influenciariam o processo de mudança, contribuindo para que suas participações fossem facilitadoras e não dificultadoras da mudança.

Os principais veículos de comunicação existentes na empresa são: Internet, perfil institucional, boletinstécnicos de produtos dirigidos ao público externo. Dirigidas ao público interno, têm-se intranet, house organ (informativo interno) e reunião semestral de executivos. As ações de comunicação são compartilhadas entre Recursos H umanos (comunicação interna) e Marketing (comunicação externa).

Algumas ações desenvolvidas tiveram base nos instrumentos já existentes na empresa, tais como:

1 À época do estudo, a Oxiteno tinha unidades fabris apenas no Brasil. Em dezembro de 2003, a empresa passou a atuar também com duas fábricas no México. 


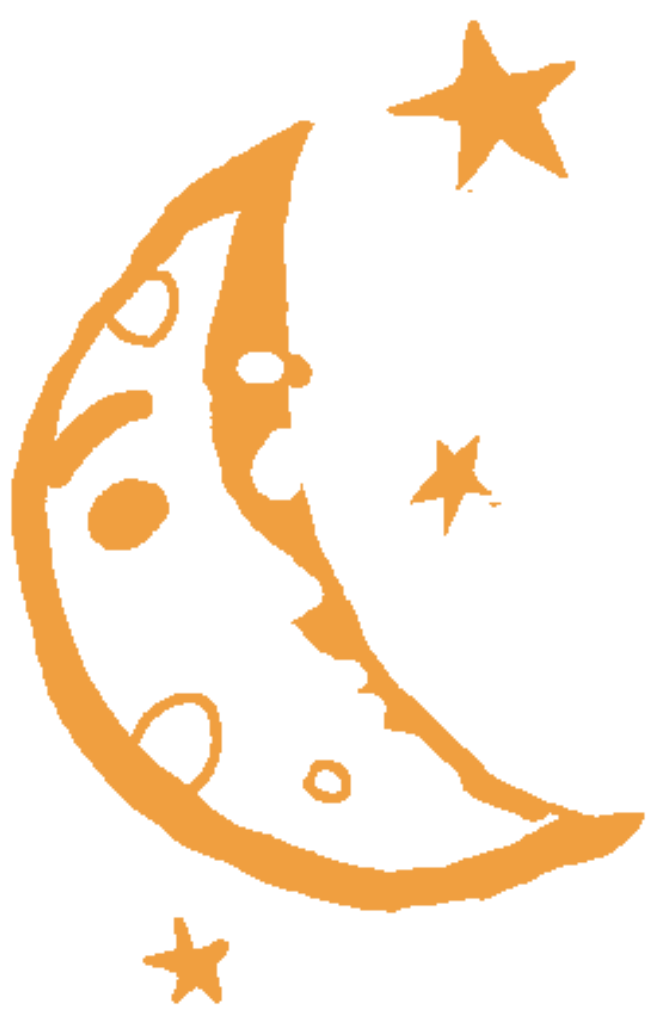

- House organ (informativo mensal, 8 páginas, tiragem de 1100 exemplares);

- E-mail e intranet (acessíveis a 70\% dos funcionários) e

- Pesquisa de clima (instrumento utilizado para diagnosticar pontos de melhoria na dinâmica da equipe do projeto, direcionado principalmente a aspectos comportamentais e de comunicação).

No entanto, frente à grande mudança, sentiu-se a necessidade de serem usados novos veículos que garantissem agilidade e confiabilidade na circulação de informações, como citado a seguir:

- Campanhas de sensibilização nas fases de transição do projeto (4 fases);

- Palestras de acompanhamento também nas fases de transição;

- Reuniões por grupo de interesse com diretores, gerentes, equipe de projeto e validadores, cuja periodicidade foi definida conforme demanda;

- Reuniões do grupo de projeto com áreas de origem e

- Boletins de informação ao mercado, por ocasião da implementação da mudança.

Estas açõesforam fundamentais para tornar o projeto conhecido e seus objetivos compreendidos em todos os níveis da organização. É comum, em empresas que não investem em comunicação, que as forças voltadas para mudança fiquem concentradas na equipe de projeto. Assim, as resistências - normais diante de uma grande mudança - afloram num momento inadequado, numa fase fatal para o sucesso do projeto: a implantação. Se neste momento, os agentes envolvidos na mudança não estiverem favoráveis às novidades, o fracasso do projeto pode ser inevitável. 
A equipe do projeto foi constituída por 47 pessoas, sendo duas (2) ligadas a gestão de mudanças (comunicação, treinamento e gestão de impactos organizacionais).

Para que as ações de comunicação tenham sucesso, é importante ressaltar a participação não só da equipe de comunicação, mas também de agentes de diversos níveis da organização, sendo suas atuações variáveis conforme o momento e os envolvidos.

\section{Resultados Observados}

Os resultados da pesquisa (aplicação de questionário a 20 funcionários e entrevista concedida pelo gerente do projeto) mostram que os motivos citados espontaneamente pelos pesquisados demonstraram alta aderência ( $90 \%$ ) ao que foi comunicado.

Quando os funcionários foram questionados sobre os meios de informação mais importantes, a maioria citou as palestras (vide gráfico 1). O bservamos que a confiança na interação pessoal confere credibilidade ao processo. 0 compromisso da 'pessoa jurídica' é importante, mas o fato de um facilitador da mudança criar oportunidades de interação demonstra segurança e é mais impactante.

\section{Gráfico 1 - Meios de informação mais importantes - citação espontânea}

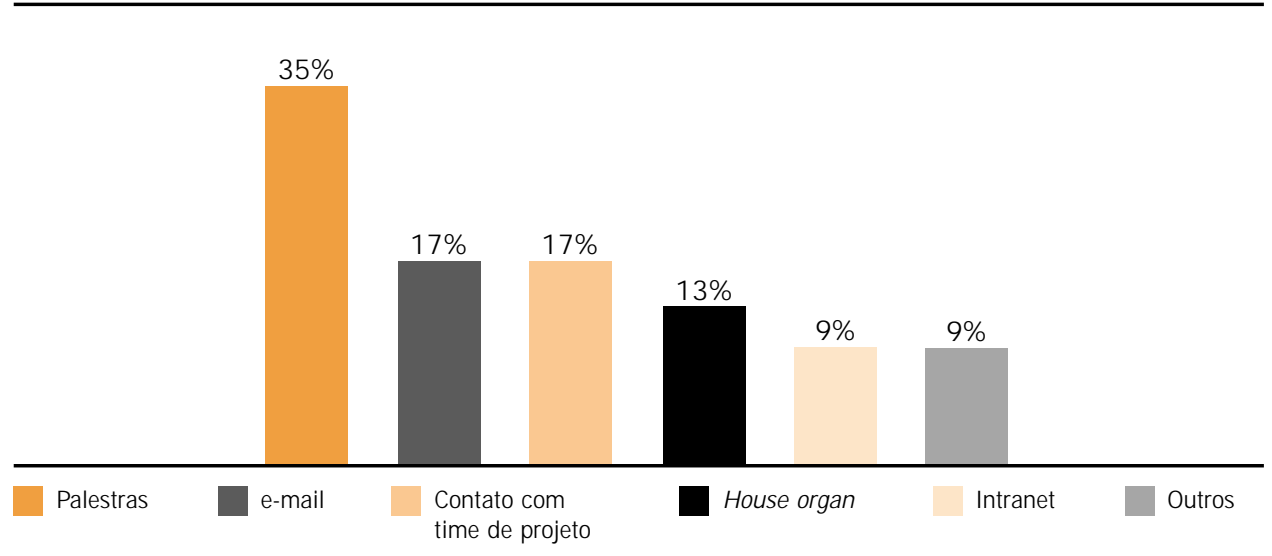

Entre os pesquisados, $80 \%$ consideraram importante ou muito importante ter informações sobre o projeto para compreender o próprio papel na mudança (vide gráfico 2), o que reforça a relevância de que cada funcionário seja visto como elemento ativo na constituição do futuro da organização. 


\section{Gráfico 2 - Importância das informações na compreensão do próprio papel}



Analisando a perspectiva de comunicação adotada pela empresa, podemos perceber que é em grande parte al inhada à teoria dos estudos culturais, uma vez que desde os estudos preliminares para avaliação de viabilidade da mudança, houve envolvimento dos vários níveis da organização.

A variedade de ações de comunicação considerou a diversidade de públicos e demandas e facilitou a minimização de resistências de grupos de indiferentes ou opositores da mudança.

Segundo o gerente do projeto, se não houvesse comunicação que reforçasse a visão da empresa, "(...) o alvo teria sido móvel e nunca conseguiríamos atingi-lo".

Podemos observar abaixo como as ações de comunicação na gestão desta mudança contribuíram para que os objetivos do projeto fossem atingidos.

\section{Tabela 1 - Objetivos do projeto versus contribuições da comunicação}

\begin{tabular}{ll}
\hline OBJETIVOS DO PROJ ETO & CONTRIBUIÇÕES DA COMUNICAÇÃo \\
\hline Comprometimento das lideranças & $\begin{array}{l}\text { A comunicação minimizou conflitos, boatos, } \\
\text { delações e ruídos. Facilitou a tomada de decisão } \\
\text { e o alinhamento para a realização da visão. }\end{array}$ \\
\hline $\begin{array}{l}\text { Disponibilizar competências-chave } \\
\text { para o projeto }\end{array}$ & $\begin{array}{l}\text { A atração de pessoas capazes e interessadas } \\
\text { em contribuir para a consecução das melhores } \\
\text { soluções foi possibilitada pelo conhecimento } \\
\text { das metas estabelecidas. }\end{array}$ \\
\hline
\end{tabular}


Ter pessoas e áreas alinhadas com o projeto
As pessoas foram informadas constantemente sobre os objetivos e 0 andamento do projeto.

0 posicionamento ético perante os funcionários da empresa facilitou o alinhamento à visão estabelecida pela alta administração.
Assegurar adequada capacitação das pessoas

Além do treinamento, a comunicação teve papel relevante para preparar as pessoas para o novo contexto, pela divulgação dos novos critérios e valores considerados importantes pela companhia.
Atrasos no projeto poderiam representar significativos prejuízos financeiros. A comunicação contribuiu para unir forças em torno do objetivo comum e torná-lo real.

Minimizar projetos concorrentes Monitoramento dos influenciadores de opinião, no intuito de facilitar as negociações e decisões foi fator fundamental para que a alta administração tivesse consciência da importância e prioridades do projeto.

Minimizar riscos do projeto frente a clientes e fornecedores
A comunicação formal aos clientes e fornecedores sobre o escopo e impacto do projeto ocorreu de forma discreta. A abordagem dos funcionários que tinham relacionamento direto com estes públicos parece ter sido mais significativa.
Garantir o comprometimento dos parceiros (fornecedor do software e consultoria implementadora)
O fato de haver reuniões da equipe de projeto, treinamento para construção do time e reuniões de mudança de fase contribuiu para a transparência na comunicação e alinhamento de objetivos.

Consideramos que, para efeito de medição de resultados, os desafios do projeto foram superados. E vários aspectos estão ligados a comunicação, quais sejam:

- A mudança foi implementada de forma eficientee com agilidade, o que evitou demanda de mais investimentos e tempo além do previsto;

- A comunicação permitiu a integração entre as frentes de trabalho o que, conseqüentemente, se revela no resultado do trabalho: integração entre os módulos do sistema;

- Foi conseguida a minimização das customizações (adaptações do softwareàs necessidades dos clientes); há nisto alguma responsabilidade da comunicação, uma vez que ficou claro para os funcionários que a redução de custo era fundamental; 
- Tempos atrás, uma mudança como esta levaria anos para ser conduzida. No entanto, se desde a concepção até a implantação, decorrer muito tempo, corre-se o risco de implantar algo que não faz mais sentido para a empresa, considerando a velocidade atual das mudanças. Portanto, dentro do possível, o cronograma de um projeto desta magnitude (envolvendo muitos funcionários, grandes mudanças operacionais e investimento financeiro significativo) deve ser reduzido. No caso citado, graças à mobilização dos envolvidos no projeto, o cronograma (10 meses de projeto) pôde ser cumprido.

Observamos que a obtenção da participação foi uma tônica do projeto, com a conquista do comprometimento de várias áreas e níveis da organização. Estes aspectos reforçam a importância da participação das pessoas como sujeitos (participantes ativos) e não como objetos (passivos) no processo de construção do futuro, o que vinculamos ao modelo de comunicação baseado nos estudos culturais. A construção ea mudança se fazem pela participação da sociedade, aceitando, criticando, remodelando e provocando mudanças em seus papéis sociais.

Os bons resultados neste projeto deixam clara a contribuição da comunicação na condução de mudanças. No entanto, não podemos generalizar este investimento, tanto financeiro quanto em esforços, em todo o meio empresarial. Ainda resta muito a fazer para que a comunicação ocorra de maneira fluida nas empresas e que tenha lugar garantido em seus orçamentos.

\section{Bibliografia}

DRUCKER, Peter. 0 advento da nova organização. In Gestão do conhecimento. Harvard business review. Trad. Afonso Celso da Cunha Serra. Rio de Janeiro: Campus, 2000.

GLADSTONE, Bryan. From know-how to knowledge - The essential guide to understanding and implementing knowledge management. Dover: Industrial Society - Business Book Network, 2000.

GROUARD, Benoit. Empresa em movimento: conheça os fundamentos e técnicas de gestão da mudança. Trad. Marcia Mateu. São Paulo: Negócio Editora, 2001.

KUNSCH, Margarida Maria Krohling (org.). Obtendo resultados com Relações Públicas. São Paulo: Pioneira, 2001.

NASSAR, Paulo e FIGUEIREDO, Rubens. O que é comunicação empresarial. São Paulo: Brasiliense, 1995.

NONAKA, Ikujiro. A empresa criadora do conhecimento. In Gestão do conhecimento. Harvard business review. Trad. Afonso Celso da Cunha Serra. Rio de J aneiro: Campus, 2000.

SIQUEIRA, Elisabete Stradiotto, SPERS, Valéria Rueda Elias. Os desafios das organizações no contexto pós-moderno. revista Impulso. Piracicaba: Ed. Unimep, v.12, n.29, 2001.

TORQUATO, Gaudêncio. Comunicação empresarial/comunicação institucional - conceitos, estratégias, sistemas, estrutura, planejamento e técnicas. São Paulo: Summus, 1986. 